\title{
Evaluation of Undrained Bearing Capacities of Wide-Shallow Bucket Foundation with Honeycomb Bulkheads in Clay
}

\author{
Qingshan Wang $\mathbb{D}^{1},{ }^{1}$ Xun Han $\mathbb{D}^{1},{ }^{1}$ Yunfei Guan, ${ }^{1}$ Yongyong Cao $\mathbb{D D}^{1},{ }^{1}$ and Wenxuan Li ${ }^{2}$ \\ ${ }^{1}$ Geotechnical Engineering Department, Nanjing Hydraulic Research Institute, Nanjing, Jiangsu 210024, China \\ ${ }^{2}$ Technology Center, Offshore Wind Power Engineering Technology Limited Company of Jiangsu Daoda, Nantong, \\ Jiangsu 226000, China \\ Correspondence should be addressed to Qingshan Wang; qswang@nhri.cn and Xun Han; xhan@nhri.cn
}

Received 4 June 2019; Accepted 24 August 2019; Published 6 December 2019

Academic Editor: Hossein Moayedi

Copyright (c) 2019 Qingshan Wang et al. This is an open access article distributed under the Creative Commons Attribution License, which permits unrestricted use, distribution, and reproduction in any medium, provided the original work is properly cited.

\begin{abstract}
As a new type of offshore wind foundation, the wide-shallow bucket foundation with honeycomb bulkheads mainly bears vertical, horizontal, and moment loads. As yet, no systematic study has been conducted regarding the effects of honeycomb bulkheads on the undrained bearing capacities of the wide-shallow bucket foundation. In this study, a large number of three-dimensional (3D) finite element (FE) analyses were performed to investigate the undrained bearing capacities of the wide-shallow bucket foundations with and without honeycomb bulkheads, thereby evaluating the influence of honeycomb bulkheads on the bearing capacities under different conditions. The results show that under uniaxial loading, the uniaxial bearing capacities of the wide-shallow bucket foundation are basically unaffected by the honeycomb bulkheads in homogeneous clay. For nonhomogeneous clay, the moment bearing capacity will be considerably enhanced with the increase in soil shear strength heterogeneity. Under combined loading, the honeycomb bulkheads will enhance the combined bearing capacities only in nonhomogeneous clay. The enhancement effects will increase with the increase in soil shear strength heterogeneity but decrease with the increase in vertical load. Besides, the simplified equations for calculating the uniaxial bearing capacities of the wide-shallow bucket foundation with honeycomb bulkheads are also proposed considering the influence of embedment ratio and soil shear strength heterogeneity. At last, the parameters of an approximating expression are fitted to predict the failure envelopes of this foundation under combined loading.
\end{abstract}

\section{Introduction}

As the global energy crisis continues to worsen, a source of renewable and clean energy, offshore wind energy, provides new possibilities to ease the current demands for energy and has been attracting attentions around the world. Hence, the construction of offshore wind turbines gradually becomes the subject of extensive researches, particularly the design and implementation of offshore wind foundations.

In terms of loading conditions in ocean engineering, the offshore wind foundation is different from the foundations of oil/gas platform, dock, and breakwater. Besides the vertical load from upper turbine and tower, this foundation also has to bear the huge horizontal and moment loads. The offshore wind foundations commonly and currently used include the monopile foundation, gravity foundation, tripod foundation, and bucket foundation. Among these, the bucket foundation is an upside-down bucket with thin skirt around the circumference. As an efficient alternative for offshore wind foundations, it can adapt to deeper waters and larger offshore wind turbines [1]. The advantages of the bucket foundation also include relatively low cost, environmental protection, and fast construction and installation [2].

The bearing capacity of the bucket foundation in undrained clay is fundamentally important in many geotechnical problems [3-5]. Hung et al. [6] performed FE analyses to evaluate the influence of embedment ratio and nonhomogeneity of clay on the bearing capacities and define the failure envelopes under combined loading. Gourvenec et al. [7] used failure envelopes to define the bearing capacity of the bucket foundation. The failure envelope approach was 
also proved to be an effective method for determining the state of the ultimate bearing capacities of the foundation under combined vertical-horizontal-moment (VHM) loading. Liu et al. [8] compared the undrained bearing capacities of the wide-shallow bucket foundation with the narrow-deep bucket foundation under combined loading. The results showed that the wide-shallow bucket foundation has obvious advantages in resisting horizontal and moment loads. Some researchers also have conducted research in depth on the bearing capacities of the bucket foundation and illustrated that the soil plug inside the bucket foundations without bulkheads is more likely to suffer from shear failure and reduces the bearing capacities [9-12]. However, these investigations mainly focused on the bucket foundation without bulkheads, while the number and form of bulkheads can influence the bearing characteristics of foundation as showed by Mana et al. [13] that the critical number of internal bulkheads inside the skirted foundation can be considerably affected by embedment ratio, vertical load, and soil shear strength heterogeneity.

In recent years, scholars have mainly carried out experimental methods [14-21] and numerical simulations [22-26] to study the bucket foundation with honeycomb bulkheads. In terms of the bearing capacities, Lian et al. [18] evaluated the influence of honeycomb bulkheads on the uniaxial bearing capacities by $1 \mathrm{~g}$ model tests. The results showed that honeycomb bulkheads can slightly enhance the vertical ultimate bearing capacity and effectively improve the antioverturning and antisliding ability. Le et al. [25] studied the bearing capacities of two concrete bucket foundations by FE method. The results showed that honeycomb bulkheads have little influence on the bearing capacities when the load is relatively small, but with increasing load, the effect of the honeycomb bulkheads on the bearing capacities becomes increasingly obvious, resulting in a $6.9 \%$ enhancement in the vertical ultimate bearing capacity, $18.3 \%$ enhancement in the horizontal bearing capacity, and $16.5 \%$ enhancement in the moment bearing capacity. Sun et al. [26] compared the vertical capacity and bearing characteristics between the bucket foundations with and without honeycomb bulkheads. The research results showed that the vertical bearing behaviour of the bucket foundation with honeycomb bulkheads is obviously different from that without bulkheads because of the distinctive structure of the former. As yet, no systematic study has been conducted regarding the effects of honeycomb bulkheads on the undrained bearing capacities of the bucket foundation in clay. The effects of the honeycomb bulkheads on the undrained bearing capacities remain unclear and must be further researched.

In this study, we established a series of 3D FE models of the wide-shallow bucket foundations with and without bulkheads to investigate the undrained bearing capacities under uniaxial and combined loadings and evaluate the effect of honeycomb bulkheads on the undrained bearing capacities. Based on the simulation results, the simplified equations for calculating the uniaxial bearing capacities of the bucket foundation with honeycomb bulkheads were proposed. At last, the failure envelopes of this foundation were predicted by an approximate expression.

\section{Numerical Modeling}

2.1. Model Geometry and Mesh. At present, eleven 3.3 MW and two $6.45 \mathrm{MW}$ offshore wind turbines are operating with a new type of large-diameter shallow buried bucket foundationcomposite bucket foundation (CBF) at Dafeng Wind Farm, Jiangsu province, China. This foundation is composed of three parts: the curved transition segment (upper, yellow), beam-slab structure (middle, light grey), and thin-walled steel bucket structure (lower, rust-colored) (Figure 1(a)). The transition segment and beam-slab are reinforced concrete structures, and the lower steel bucket is a large-diameter cylindrical bottomless structure. The steel buckets diameters of the $13 \mathrm{CBF}$ mostly range between 30 and $36 \mathrm{~m}$, and the heights mostly range between 8 and $12 \mathrm{~m}$. Therefore, different from the traditional narrow-deep bucket foundation, this foundation is a typical wide-shallow bucket foundation. In order to control the balance during the towing and sinking process, the bucket is subdivided to compartments, and each compartment can be independently controlled. In this case, the steel bucket is divided into seven compartments by honeycomb bulkheads, as presented in Figure 1(b).

In this study, the FE analyses were carried out with the commercial software ABAQUS 6.14. Since the main research object was steel bucket and the load carried by the CBF can be concentrated to a certain point, the transition segment and beam-slab structure were not considered when establishing the FE model. Only the precise 3D FE models of steel bucket foundations with and without honeycomb bulkheads were established, as shown in Figures 2(a) and 2(b).

Taking the practical engineering in this study for instance, bucket foundation embedment ratios mainly concentrate in 0.2-0.4. In order to further evaluate the undrained bearing capacities of the wide-shallow bucket foundation, embedment ratio equalling 0.1 and 0.5 was also added into this study. Therefore, we set the embedment ratios of the wide-shallow bucket foundation $d / D$ as $0.1,0.2$, $0.3,0.4$, and 0.5 , where $D$ and $d$ is the diameter and embedment depth of the steel bucket, respectively. Previous studies indicated that $D$ has no effect on the normalized bearing capacity [6]. By taking the actual size of the $3.3 \mathrm{MW}$ offshore wind turbine in Dafeng Wind Farm as a reference, the foundation diameter $D$ was set to be a constant $30 \mathrm{~m}$ for the numerical modeling. We set the steel plate thickness of the bucket wall as $25 \mathrm{~mm}$, the steel plate thickness of the bulkheads as $15 \mathrm{~mm}$, and the steel plate thickness of the bucket lid as $6 \mathrm{~mm}$. To reduce the boundary effect of the FE model, we designed the diameter as $8 D$ and depth as $8 d$ for the selected soil. Because the hybrid element is more suitable for simulating incompressible materials like undrained clay [27], we used C3D8H solid element to model the undrained clay, and the steel bucket in the model used shell element. The bottom boundary of the soil was fully fixed for the $x, y$, and $z$ directions, while the lateral boundary was only allowed to have vertical displacement. The mesh generation of the FE model is shown in Figure 2(c).

The stiffness of the steel bucket is much larger than that of the soft ground, and this study focuses on the bearing capacity of the bucket foundation, so the bucket foundation 


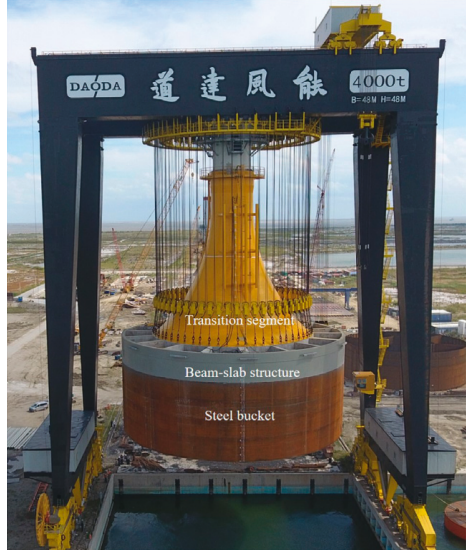

(a)

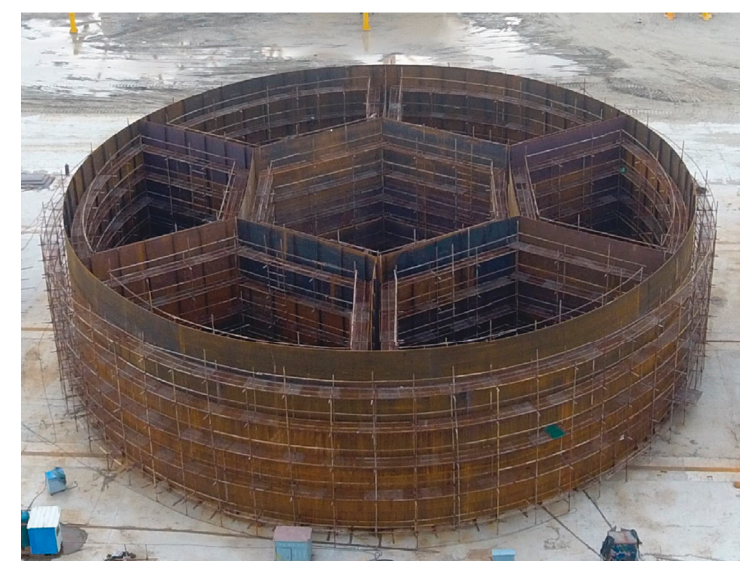

(b)

Figure 1: The pictures of CBF. (a) Structure of the CBF. (b) Internal honeycomb bulkheads.

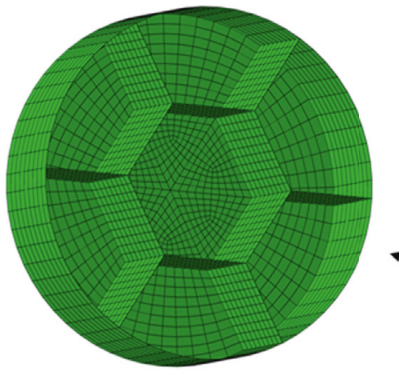

(a)

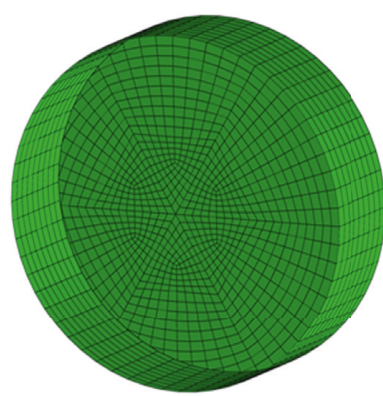

(b)

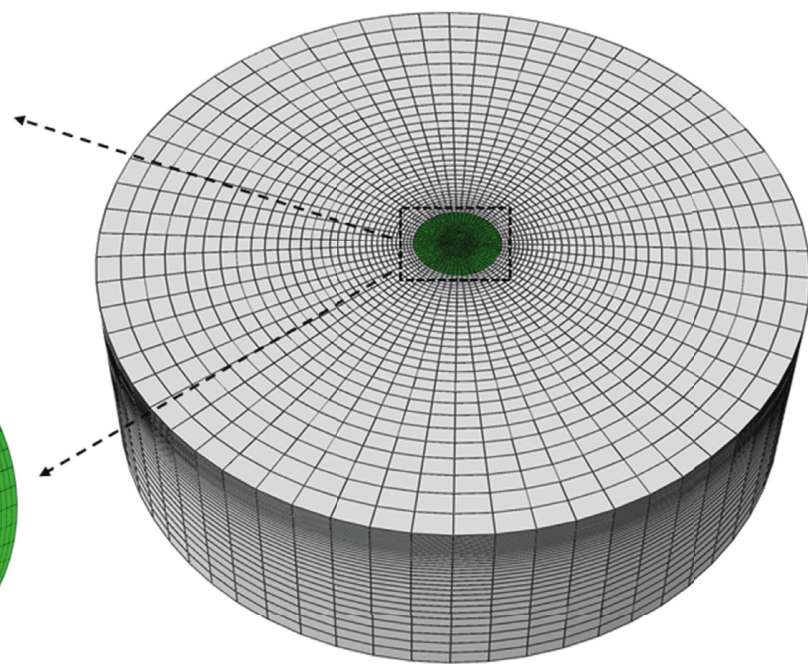

(c)

Figure 2: Example of the FE mesh $(d / D=0.3)$. (a) Bucket foundation with honeycomb bulkheads. (b) Bucket foundation without bulkheads. (c) Soil and foundation model.

can be deemed a rigid body $[28,29]$. The central point of the foundation bottom was set as the reference point (RP), as suggested in previous studies [5, 6, 30, 31]. All uniaxial loadings act on RP, as shown in Figure 3.

This is not a bucket foundation having central symmetrical structure because of the honeycomb bulkheads. In this case, the impact of loading direction on the undrained bearing capacities needs to be considered. Since the moment acting on the bucket foundation is always caused by the horizontal load, the moment and the horizontal loads are always in the same load plane. We defined the intersection angle between the bulkheads and the load plane as $\alpha$ and the counterclockwise direction as the forward direction, as shown in Figure 4. The effect of different loading direction angles on bearing capacities was analysed by changing $\alpha$. Figure 4 shows the horizontal bearing capacity factor and moment bearing capacity factor in different intersection angles for $d / D=0.3$ and $\kappa=6$. The results show that the undrained bearing capacities are almost unaffected by $\alpha$. Thus, both the horizontal loading and moment loading were loaded according to $\alpha=0$ load plane in this study.

2.2. Material Properties. For the ultimate bearing capacity analysis on the basis of the undrained condition, an ideal elastic-plastic constitutive model based on the Tresca failure criterion ( $\varphi=0$ condition) was adopted for the saturated soft clay $[4,5]$. Suppose the soil undrained shear 


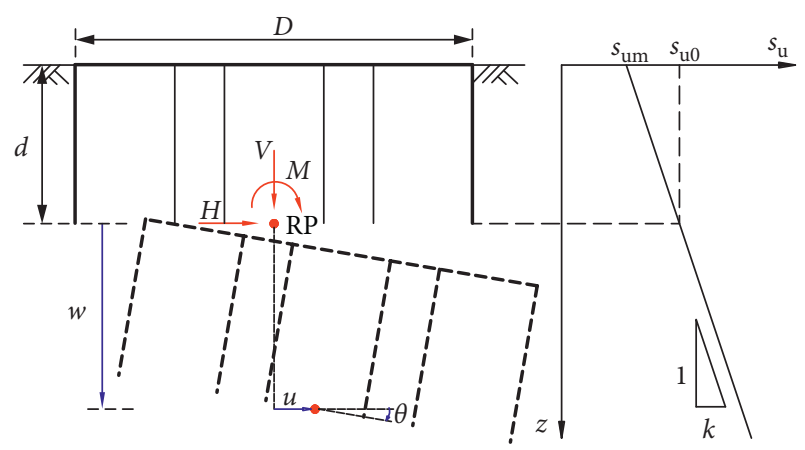

FIGURE 3: Reference point, soil undrained shear strength profile, and sign convention.

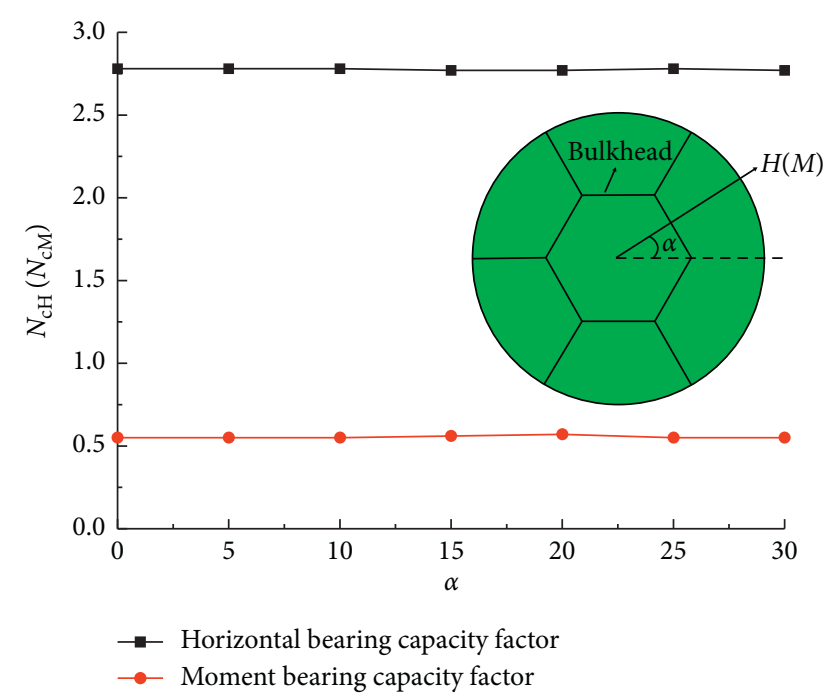

Figure 4: Bearing capacity factors in different intersection angles $(d / D=0.3, \kappa=6)$.

strength $s_{\mathrm{u}}$ varies linearly with depth, as shown in the following equation:

$$
s_{\mathrm{u}}=s_{\mathrm{um}}+k z
$$

where $s_{\text {um }}$ is the undrained shear strength at the mud surface and $k$ is the increasing rate of strength with depth $z$, as presented in Figure 3.

Research results have shown that bearing capacity factors are independent of individual parameters $s_{\text {um }}$ or $k$ but are related to normalized parameters of $k D / s_{\text {um }}$ [31]. Therefore, the soil shear strength heterogeneity index $\kappa$ was introduced:

$$
\kappa=\frac{k D}{s_{\text {um }}} .
$$

According to the value of $\kappa$ in practice, the research was conducted by taking $\kappa=0$ (homogeneous clay), 3, 6, 12, and 30. The soil elastic modulus $E_{\mathrm{u}}=500 s_{\mathrm{u}}$; the Poisson's ratio was set to be 0.499 for simulating the constant volume response of undrained clay [30, 31]; and the effective unit weight was fixed at $6 \mathrm{KN} / \mathrm{m}^{3}$. These values are typical indicators of saturated soft clay.

This study assumed that the steel bucket lid was resting on the soil. As both the suction effect of the bucket foundation and the permeability coefficient of the soft clay are small, and the bond between the foundation and soil is strong, the foundation-soil interface was assumed to be fully rough, namely separation was not permitted $[4,6,10,30,31]$.

2.3. Sign Convention and Notation. The sign convention for loads and displacements in this study obeys a right-handed axis and clockwise positive convention, as proposed by Butterfield et al. [32] (Figure 3). Table 1 shows the notation adopted in this study.

2.4. Loading Methods and Paths. In this study, we placed loads on the bucket foundation through the displacementcontrol method. The displacement-control method was more suitable for the bucket foundation bearing capacities study than the load-controlled method [5-7]. FE analyses in this study were carried out in three steps. In the first step, geostatic stresses were applied to the free-field soil elements for avoiding displacement under gravity. In the second step, the soil elements within the steel bucket geometry were replaced with bucket elements, and the interface between the bucket and soil was activated. The bucket foundation was assumed to be "wished in place," i.e., neglecting the bucket foundation installation process. In the final step, the displacement at the RP was increased until failure was reached.

For uniaxial loading, the tangent intersection method is used for getting the ultimate bearing capacity $[6,33]$. In this method, the ultimate bearing capacity was defined as the load corresponding to the intersection point of two tangential lines along the initial and latter portions of the loaddisplacement curve. For combined VHM loading, we apply the probe loading method with fixed displacement to solve failure envelope, which is divided into two steps. In the first step, we applied the fixed loading on the RP; for example, we set $v$ to be $0,0.25,0.5$, and 0.75 . In the second step, in order to construct the failure envelope, a series of constant $u / D \theta$ ratio displacement probes were used. Usually, about 10 probe tests are needed to obtain a failure envelope. An example of determining a capacity failure envelope using the probe method is shown in Figure 5.

2.5. Validation. In this study, the FE analysis accuracy was validated by comparing with the bearing capacity results from the theoretically solutions and experimental tests.

Martin [34] suggested exact theoretically solutions of the vertical bearing capacity for the circular surface foundation. Vertical bearing capacity factors of the solid circular foundations without embedment predicted from FE analyses were compared with Martin's [34] theoretically solutions, as shown in Table 2. The results show that for a range of soil shear strength heterogeneity, the FE results for vertical bearing capacity factors agreed to within $5 \%$ of the exact theoretically solutions.

Coffman et al. [35] studied the horizontal bearing capacity and failure mode of bucket foundation in nonhomogeneous clay using $1 \mathrm{~g}$ model tests. The model tests were carried out using a $0.1 \mathrm{~m}$ diameter bucket foundation installed to a depth about $0.8 \mathrm{~m}$ in normally consolidated kaolinite clay and 
TABLE 1: Notation for loads and displacements.

\begin{tabular}{lccc}
\hline & Vertical & Horizontal & Rotational \\
\hline Displacement & $w$ & $u$ & $\theta$ \\
Load & $V$ & $H$ & $M$ \\
Uniaxial capacity & $V_{\mathrm{ult}}$ & $H_{\mathrm{ult}}$ & $M_{\mathrm{ult}}$ \\
Bearing capacity factor & $N_{\mathrm{cV}}=V_{\mathrm{ult}} / A s_{\mathrm{u} 0}$ & $N_{\mathrm{cH}}=H_{\mathrm{ult}} / A s_{\mathrm{u} 0}$ & $N_{\mathrm{cM}}=M_{\mathrm{ult}} / A D s_{\mathrm{u} 0}$ \\
Dimensionless load & $V / A s_{\mathrm{u} 0}$ & $H / A s_{\mathrm{u} 0}$ & $M / A D s_{\mathrm{u} 0}$ \\
Normalized load & $\nu=V / V_{\mathrm{ult}}$ & $h=H / H_{\mathrm{ult}}$ & $m=M / M_{\mathrm{ult}}$ \\
\hline
\end{tabular}

Note. $A=\pi D^{2} / 4 ; s_{\mathrm{u} 0}$ is the undrained shear strength at the foundation bottom level.

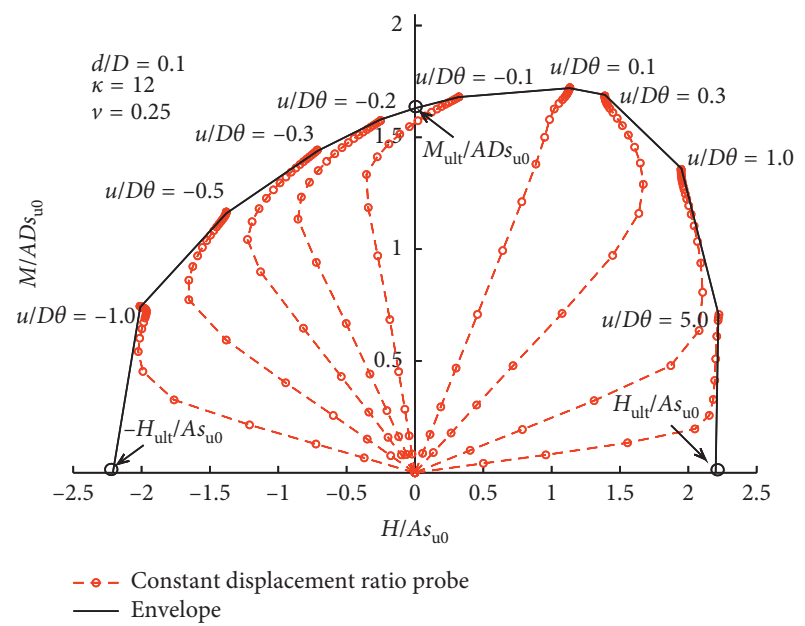

FIgURE 5: Example of a failure envelope using probe tests $(d / D=0.1$, $\kappa=12$, and $\nu=0.25$ ).

allowed to set up for 48 hours prior to testing. Nine model tests were performed with various heights of horizontal loads on the bucket foundation. Table 3 compares the ultimate horizontal bearing capacity between the FE results and Coffman et al.'s [35] research results. The results present good agreement between the FE analyses and the model tests.

To further investigate, the FE model of bucket foundation with bulkheads was validated with the results of largescale model tests by Liu [36]. In the test, the model bucket foundation with a diameter of $D=3.5 \mathrm{~m}$, an embedment depth of $d=0.9 \mathrm{~m}$, and steel plate thickness of $8 \mathrm{~mm}$ located in saturated silt clay. The seven compartments were divided inside the steel bucket by bulkheads. The tests were carried out with a horizontal loading eccentricity as $3 \mathrm{~m}$ and $4 \mathrm{~m}$, respectively. Table 3 shows that the horizontal bearing capacity errors between FE results and test results of Liu [36] are controlled within $6.7 \%$.

According to the above comparisons, the results achieved from the FE analyses properly agree with those obtained from experimental tests. Consequently, the FE method applied in this study was suitable and reliable for analysing the undrained bearing capacities.

\section{Uniaxial Capacities}

\subsection{Undrained Vertical Bearing Capacity}

3.1.1. Effect of Honeycomb Bulkheads on Undrained Vertical Bearing Capacity. To reflect the effect of the honeycomb
TABLE 2: Comparison of vertical bearing capacity.

\begin{tabular}{lccc}
\hline$\kappa$ & This study & $N_{\mathrm{cV}}$ & Error (\%) \\
\hline 0 & 6.20 & Martin [34] & 2.42 \\
3 & 8.53 & 8.05 & 2.81 \\
6 & 10.15 & 9.85 & 2.96 \\
12 & 12.91 & 12.47 & 3.41 \\
30 & 19.93 & 18.98 & 4.77 \\
\hline
\end{tabular}

bulkheads on the undrained vertical bearing capacity, we defined the bulkhead efficiency factor of the vertical bearing capacity $\delta_{\mathrm{cV}(d / D, \kappa)}$ as follows:

$$
\delta_{\mathrm{cV}(d / D, \kappa)}=\frac{N_{\mathrm{cV}(d / D, \kappa)}^{\mathrm{I}},}{N_{\mathrm{cV}(d / D, \kappa)}^{\mathrm{B}}}
$$

where $N_{\mathrm{cV}(d / D, \kappa)}^{\mathrm{I}}$ and $N_{\mathrm{cV}(d / D, \kappa)}^{\mathrm{B}}$ are the vertical bearing capacity factors of the bucket foundations with and without honeycomb bulkheads under different $d / D$ ratios and $\kappa$, respectively. If $\delta_{\mathrm{cV}(d / D, \kappa)}>1$, the honeycomb bulkheads can enhance the vertical bearing capacity. If $\delta_{\mathrm{cV}(d / D, \kappa)}=1$, the vertical bearing capacity is not affected by the honeycomb bulkheads.

Figure 6 shows the bulkhead efficiency factor of the vertical bearing capacity $\delta_{\mathrm{cV}(d / D, \kappa)}$ for different $d / D$ ratios and $\kappa$. Figure 6 shows that for homogeneous clay $(\kappa=0)$, $\delta_{\mathrm{cV}}$ is close to 1 , so the honeycomb bulkheads at this case would basically not enhance the vertical bearing capacity. This is consistent with the research results of Xiao et al. [27]. For nonhomogeneous clay, $\delta_{\mathrm{cV}}$ is close to 1 when $d /$ $D \geq 0.4$, so the bulkheads would also not enhance the vertical bearing capacity at this case; for comparatively small $d / D$ ratios, $\delta_{\mathrm{cV}}$ is slightly greater than 1 and slightly increases with the increase in $\kappa$. When $d / D=0.1$ and $\kappa=30$, the vertical bearing capacity only increases by about $5 \%$. Notably, when calculating the ultimate bearing capacity using the tangent intersection method, the drawing deviation of tangential lines may result in $2 \%-5 \%$ variation [6]. To guarantee safety in the design, the function of honeycomb bulkheads to enhance the vertical bearing capacity can be ignored.

3.1.2. Simplified Calculation Formula of Vertical Bearing Capacity. To reflect the effect of the embedment depth on the vertical bearing capacity of the bucket foundation with honeycomb bulkheads, the depth factor of the vertical bearing capacity $d_{\mathrm{cV}}$ was introduced, as shown in 
TABLE 3: Comparison of horizontal bearing capacity.

\begin{tabular}{|c|c|c|c|c|}
\hline \multirow{2}{*}{ Depth of bucket embedment (m) } & \multirow{2}{*}{ Height to loading point (m) } & \multicolumn{2}{|c|}{$H_{\text {ult }}(\mathrm{KN})$} & \multirow{2}{*}{ Error $(\%)$} \\
\hline & & This study & Coffman et al. [35] & \\
\hline 0.813 & 0.533 & 0.342 & 0.330 & 3.51 \\
\hline 0.805 & 0.381 & 0.196 & 0.187 & 4.60 \\
\hline 0.820 & 0.610 & 0.345 & 0.328 & 4.93 \\
\hline \multirow{2}{*}{$d / D$} & \multirow{2}{*}{ Height to loading point (m) } & \multicolumn{2}{|c|}{$H_{\text {ult }}(\mathrm{KN})$} & Frror (\%) \\
\hline & & This study & Liu [36] & Error (\%) \\
\hline 0.26 & 3.0 & 34.51 & 36.82 & 6.70 \\
\hline 0.26 & 4.0 & 27.15 & 28.89 & 6.41 \\
\hline
\end{tabular}

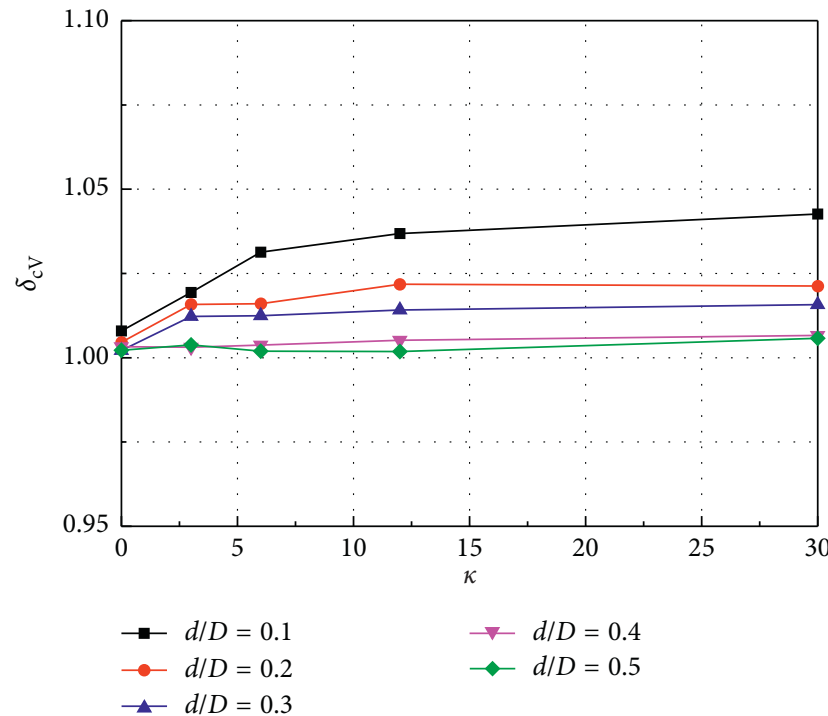

Figure 6: Effect of honeycomb bulkheads on vertical bearing capacity.

$$
d_{\mathrm{cV}}=\frac{N_{\mathrm{cV}(d / D, \kappa)}^{\mathrm{I}}}{N_{\mathrm{cV}(d / D=0, \kappa)}}
$$

where $N_{\mathrm{cV}(d / D=0, \kappa)}$ is the vertical bearing capacity factor of circular foundation without embedment.

We substituted $N_{\mathrm{cV}(d / D, \kappa)}^{\mathrm{I}}$ and $N_{\mathrm{cV}(d / D=0, \kappa)}$ solved by numerical simulation into equation (4) to obtain the depth factor $d_{\mathrm{cV}}$ and then fit $d_{\mathrm{cV}}$ with $d / D$ and $\kappa$ to obtain the fitting formula as follows:

$$
d_{\mathrm{cV}}=\frac{a_{1}+0.53(d / D)-0.035 \kappa(d / D)}{b_{1}+0.1(d / D)-0.43(d / D)^{2}+0.073 \kappa(d / D)},
$$

where $\quad a_{1}=1.25+0.16 \kappa+0.0033 \kappa^{2}, \quad b_{1}=1+0.1 \kappa+0.01 \kappa^{2}$, $0.1 \leq d / D \leq 0.5$, and $0 \leq \kappa \leq 30$. The comparison of the fitted curve and the FE results is shown in Figure 7, which indicates a high fitting precision of (5).

$N_{\mathrm{cV}(d / D=0, \kappa)}$ can be obtained according to the expression given in Vulpe et al. [4], as shown in the following:

$$
N_{\mathrm{cV}(d / D=0, \kappa)}=N_{\mathrm{cV}(d / D=0, \kappa=0)\left[1+(0.09 \kappa)^{0.76}\right]},
$$

where the value of $N_{\mathrm{cV}(d / D=0, \kappa=0)}$ is 6.05 according to the accurate solution given in Martin [34]. Then, equations (5) and (6) were substituted into equation (4) to obtain the simplified calculation equation of $N_{\mathrm{cV}(d / D, \kappa)}^{\mathrm{I}}$ as follows:

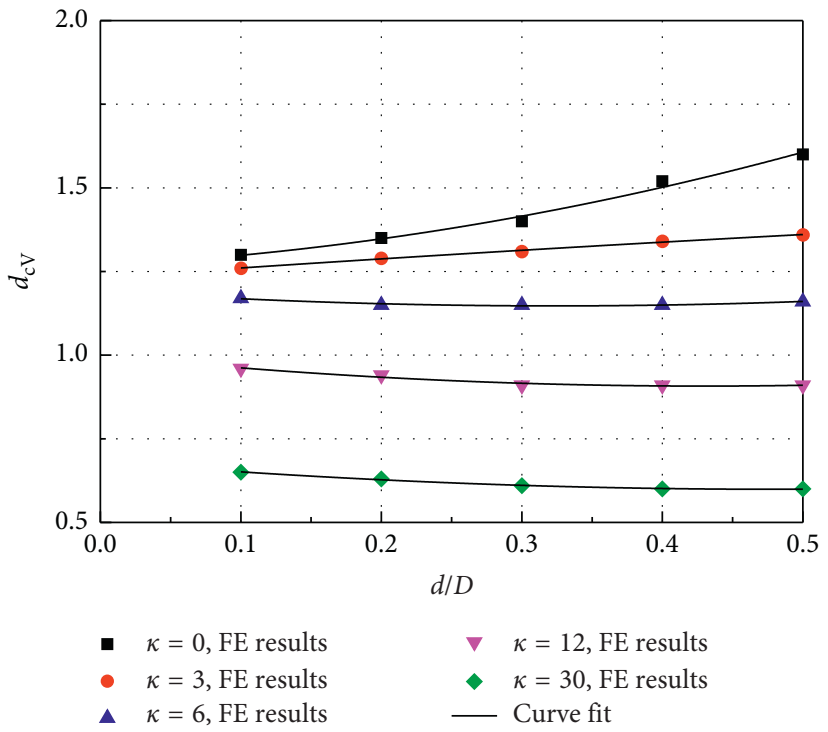

Figure 7: Depth factor of vertical bearing capacity.

$$
\begin{aligned}
& N_{\mathrm{cV}(d / D, \kappa)}^{\mathrm{I}} \\
& \quad=\frac{6.05\left[1+(0.09 \kappa)^{0.76}\right]\left(a_{1}+0.53(d / D)-0.035 \kappa(d / D)\right)}{b_{1}+0.1(d / D)-0.43(d / D)^{2}+0.073 \kappa(d / D)} .
\end{aligned}
$$

Finally, the undrained vertical ultimate bearing capacity $V_{\text {ult }}$ could be obtained using the expression $V_{\mathrm{ult}}=N_{\mathrm{cV}} A s_{\mathrm{u} 0}$.

\subsection{Undrained Horizontal Bearing Capacity}

3.2.1. Effect of Honeycomb Bulkheads on Undrained Horizontal Bearing Capacity. Similar to the calculation of the vertical bearing capacity, the bulkhead efficiency factor of the horizontal bearing capacity $\delta_{\mathrm{cH}(d / D, \kappa)}$ was defined as follows:

$$
\delta_{\mathrm{cH}(d / D, \kappa)}=\frac{N_{\mathrm{cH}(d / D, \kappa)}^{\mathrm{I}}}{N_{\mathrm{cH}(d / D, \kappa)}^{\mathrm{B}}},
$$

where $N_{\mathrm{cH}(d / D, \kappa)}^{\mathrm{I}}$ and $N_{\mathrm{cH}(d / D, \kappa)}^{\mathrm{B}}$, respectively, represent the horizontal bearing capacity factors of the bucket foundations with and without bulkheads.

Figure 8 shows the bulkhead efficiency factor $\delta_{\mathrm{cH}(d / D, \kappa)}$ for different $d / D$ ratios and $\kappa$. Figure 8 shows that for 


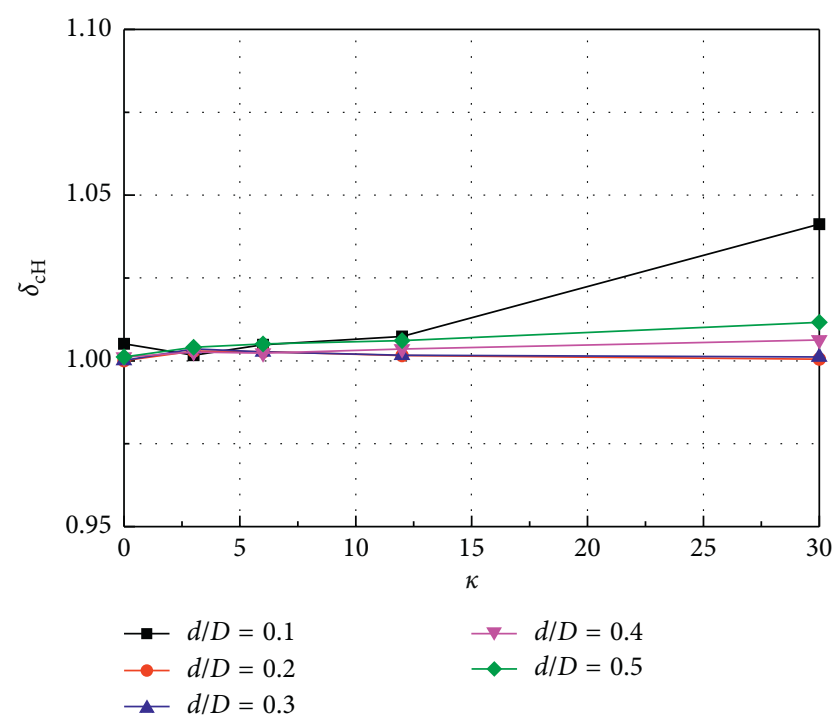

FIGURE 8: Effect of honeycomb bulkheads on horizontal bearing capacity.

homogeneous clay $(\kappa=0), \delta_{\mathrm{cH}}$ is close to 1 , so the honeycomb bulkheads would basically not improve the horizontal bearing capacity. $\delta_{\mathrm{cH}}$ almost exhibits no change, except when $d / D=0.1$ and $\kappa$ is comparatively large $(\kappa \geq 12)$. Therefore, the effect of honeycomb bulkheads on improving the horizontal bearing capacity can also be ignored.

\subsubsection{Simplified Calculation Formula of Horizontal Bearing} Capacity. The depth factor of the horizontal bearing capacity $d_{\mathrm{cH}}$ was introduced, as shown in the following:

$$
d_{\mathrm{cH}}=\frac{N_{\mathrm{cH}(d / D, \kappa)}^{\mathrm{I}}}{N_{\mathrm{cH}(d / D=0, \kappa)}},
$$

where $N_{\mathrm{cH}(d / D=0, \kappa)}$ is the horizontal bearing capacity factor of circular foundation without embedment.

$N_{\mathrm{cH}(d / D, \kappa)}^{\mathrm{I}}$ and $N_{\mathrm{cH}(d / D=0, \kappa)}$ were substituted into equation (9) to solve the depth factor $d_{\mathrm{cH}}$ and then fit $d_{\mathrm{cH}}$ with $d /$ $D$ and $\kappa$ to obtain the fitting formula, as shown:

$$
d_{\mathrm{cH}}=\frac{a_{2}+4.9(d / D)+1.37 \kappa(d / D)}{b_{2}-1.03(d / D)+0.18 \kappa(d / D)},
$$

where $a_{2}=1.61+0.35 \kappa-0.0018 \kappa^{2}, b_{2}=1+0.2 \kappa-0.00045 \kappa^{2}$, $0.1 \leq d / D \leq 0.5$, and $0 \leq \kappa \leq 30$. The comparison of the fitted curve and the FE results is shown in Figure 9. The fitting precision of equation (10) is also ideal.

In order for convenient calculation and conservative design, $N_{\mathrm{cH}(d / D=0, \kappa)}$ could be set to 1.0 , which is the theoretical lower bound solution in Gourvenec et al. [37]. Equation (10) and $N_{\mathrm{cH}(d / D=0, \kappa)}=1.0$ were substituted into equation (9) to obtain the simplified calculation equation of $N_{\mathrm{cH}(d / D, \kappa)}^{\mathrm{I}}$ as follows:

$$
N_{\mathrm{cH}(d / D, \kappa)}^{\mathrm{I}}=\frac{a_{2}+4.9(d / D)+1.37 \kappa(d / D)}{b_{2}-1.03(d / D)+0.18 \kappa(d / D)} .
$$

Finally, the horizontal ultimate bearing capacity $H_{\text {ult }}$ could be obtained by the expression $H_{\mathrm{ult}}=N_{\mathrm{cH}} A s_{\mathrm{u} 0}$.

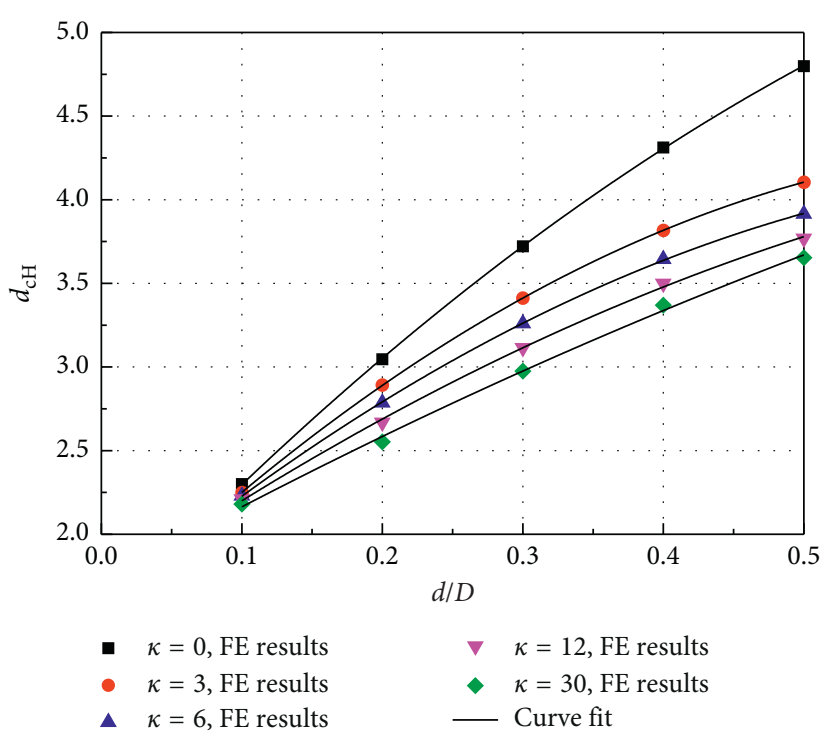

FIGURE 9: Depth factor of horizontal bearing capacity.

\subsection{Undrained Moment Bearing Capacity}

3.3.1. Effect of Honeycomb Bulkheads on Undrained Moment Bearing Capacity. The bulkhead efficiency factor of the moment bearing capacity $\delta_{\mathrm{cM}(d / D, \kappa)}$ can be defined as follows:

$$
\delta_{\mathrm{cM}(d / D, \kappa)}=\frac{N_{\mathrm{cM}(d / D, \kappa)}^{\mathrm{I}}}{N_{\mathrm{cM}(d / D, \kappa)}^{\mathrm{B}}},
$$

where $N_{\mathrm{cM}(d / D, \kappa)}^{\mathrm{I}}$ and $N_{\mathrm{cM}(d / D, \kappa)}^{\mathrm{B}}$ are the moment bearing capacity factors of the bucket foundations with and without bulkheads, respectively.

Figure 10 shows the bulkhead efficiency factor of the moment bearing capacity $\delta_{\mathrm{cM}(d / D, \kappa)}$ for different $d / D$ ratios and $\kappa$. The figure shows that for homogeneous clay $(\kappa=0)$, $\delta_{\mathrm{cm}}$ is close to 1 , so the honeycomb bulkheads would basically not increase the moment bearing capacity. However, for nonhomogeneous clay, $\delta_{\mathrm{cM}}$ could considerably increase with the increase in $\kappa$ in conditions of different $d / D$ ratios. This is different from the result of the vertical and horizontal bulkhead efficiency factors. The $\delta_{\mathrm{cM}}$ shows the maximum increase effect for $d / D=0.2$ or 0.3 , especially when $\kappa=30$, and the increase could reach around $48.5 \%$.

3.3.2. Simplified Calculation Formula of Moment Bearing Capacity. To reflect the influence of the embedment depth on the moment bearing capacity of the bucket foundation with honeycomb bulkheads, the depth factor of moment bearing capacity $d_{\mathrm{cM}}$ was introduced, as shown in the following equation:

$$
d_{\mathrm{cM}}=\frac{N_{\mathrm{cM}(d / D, \kappa)}^{\mathrm{I}}}{N_{\mathrm{cM}(d / D=0, \kappa)}},
$$

where $N_{\mathrm{cM}(d / D=0, \kappa)}$ is the moment bearing capacity factor of circular foundation without embedment. 


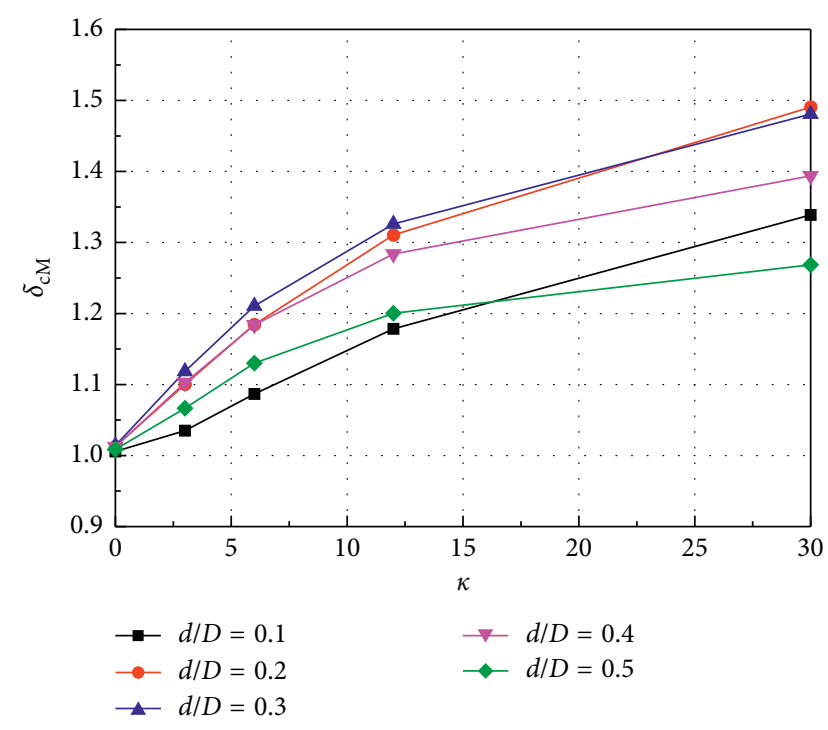

FIGURE 10: Effect of honeycomb bulkheads on moment bearing capacity.

We substituted $N_{\mathrm{cM}(d / D, \kappa)}^{\mathrm{I}}$ and $N_{\mathrm{cM}(d / D=0, \kappa)}$ into equation (13) to obtain $d_{\mathrm{cM}}$ and then fit $d_{\mathrm{cM}}$ with $d / D$ and $\kappa$ to obtain the fitting formula, as shown in the following equation:

$$
d_{\mathrm{cM}}=\frac{a_{3}+69.77(d / D)+2 \kappa(d / D)}{b_{3}+50.7(d / D)-49.11(d / D)^{2}+9.96 \kappa(d / D)},
$$

where $a_{3}=0.41+0.63 \kappa-0.022 \kappa^{2}, \quad b_{3}=1+0.34 \kappa-0.024 \kappa^{2}$, $0.1 \leq d / D \leq 0.5$, and $0 \leq \kappa \leq 30$. The comparison of the fitted curve and the FE results is shown in Figure 11. The fitting precision of equation (14) is also optimal.

$N_{\mathrm{cM}(d / D=0, \kappa)}$ can be obtained according to the expression given in Vulpe et al. [4], as follows:

$$
N_{\mathrm{cM}(d / D=0, \kappa)}=N_{\mathrm{cM}(d / D=0, \kappa=0)}\left[1+(0.21 \kappa)^{0.74}\right] \text {, }
$$

where $N_{\mathrm{cM}(d / D=0, \kappa=0)}$ can be set to 0.67 according to Randolph et al. [38]. We substituted equations (14) and (15) into equation (13) and obtained the simplified calculation equation of $N_{\mathrm{cM}(d / D, \kappa)}^{\mathrm{I}}$ as follows:

$$
N_{\mathrm{cM}(d / D, \kappa)}^{\mathrm{I}}=\frac{0.67\left[1+(0.21 \kappa)^{0.74}\right]\left(a_{3}+69.77(d / D)+2 \kappa(d / D)\right)}{b_{3}+50.7(d / D)-49.11(d / D)^{2}+9.96 \kappa(d / D)} .
$$

Finally, the moment ultimate bearing capacity $M_{\mathrm{ult}}$ could be obtained by the expression $M_{\mathrm{ult}}=N_{\mathrm{cM}} A D s_{\mathrm{u} 0}$.

\section{Combined VHM Capacity}

4.1. Effect of Honeycomb Bulkheads on Combined VHM Capacity. The dimensionless failure envelope can directly reflect the combined bearing capacities of the foundation. Therefore, the differences in the dimensionless failure envelopes of the two foundations can be compared, and the influence of the honeycomb bulkheads under different conditions can be analysed based on the comparison.

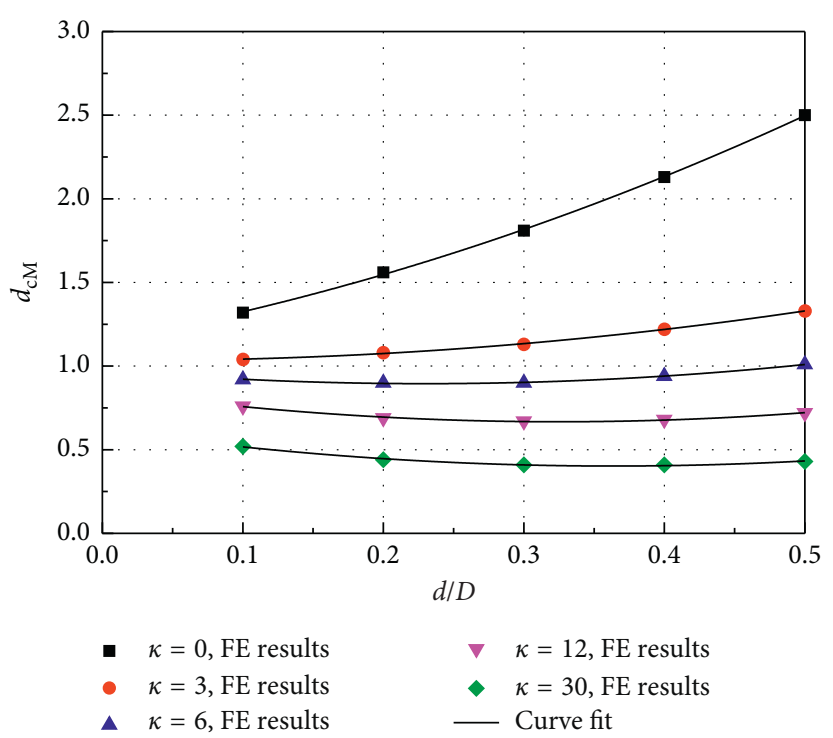

FIgURE 11: Depth factor of moment bearing capacity.

Figure 12 shows the dimensionless horizontal-moment $(H M)$ failure envelopes of the two foundations under different soil shear strength heterogeneity indexes $(\kappa=0,3$, and 30 , for instance) when $d / D=0.3$ and $\nu=0$. The figure shows that the failure envelopes of the two foundations exhibit significant asymmetry. With the increase in $\kappa$, the asymmetry of the failure envelopes decreases. For homogeneous clay $(\kappa=0)$, the failure envelopes of the two types of foundations almost overlap, indicating that the honeycomb bulkheads are basically ineffective at this time, and the results of the uniaxial capacities are also verified. However, for nonhomogeneous clay $(\kappa>0)$, all the failure envelopes of the bucket foundation with honeycomb bulkheads fall outside those of the foundation without bulkheads. This indicates that the bucket foundation with honeycomb bulkheads has a better bearing capacity. With the increase in $\kappa$, the gap between the two types of bucket foundation failure envelopes continues increasing accordingly.

Since homogeneous clay is rarely encountered in in situ conditions, we used $\kappa=12$ as an example for nonhomogeneous clay to study the influence of honeycomb bulkheads on $H M$ failure envelopes under different embedment ratios $(d / D=0.1$ and 0.5 , for instance) and different vertical loads $(\nu=0,0.25,0.5$, and 0.75 , for instance, Figure 13). The figure shows that under different $d / D$ ratios and $v$, the setting of honeycomb bulkheads has different effects on the failure envelopes.

The comparisons of Figures 13(a) and 13(b) show that for $d / D=0.1$ or $d / D=0.5$, the failure envelopes of the bucket foundation with honeycomb bulkheads are all located far away from those of the bucket foundation without honeycomb bulkheads in the first quadrant of the $H M$ load space (i.e., the $H$ and $M$ are in the same direction). That means the honeycomb bulkheads can evidently improve the bearing capacity in both $H$ and $M$ directions. When $v$ increases from 0 to $0.75, H M$ failure envelopes along $H$ - and $M$-axes all shrink, and the gaps in the failure envelopes between the two types of bucket 


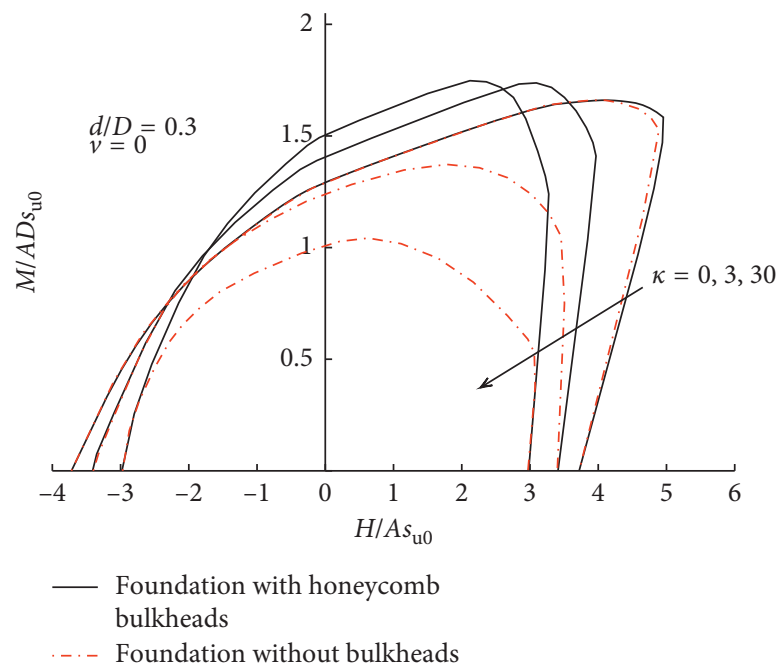

FIGURE 12: Comparison of failure envelopes under different soil shear strength heterogeneity indexes $(d / D=0.3, v=0)$.

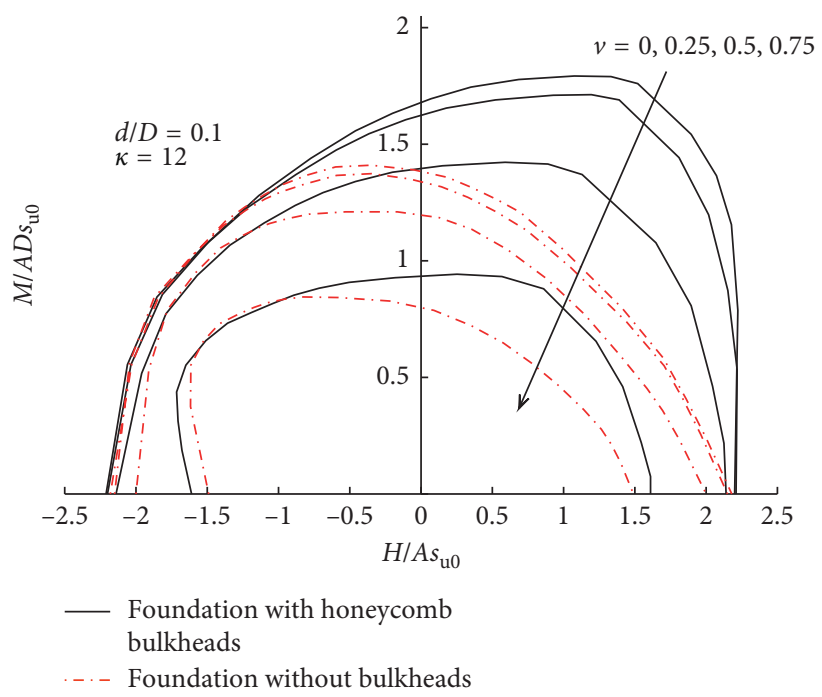

(a)

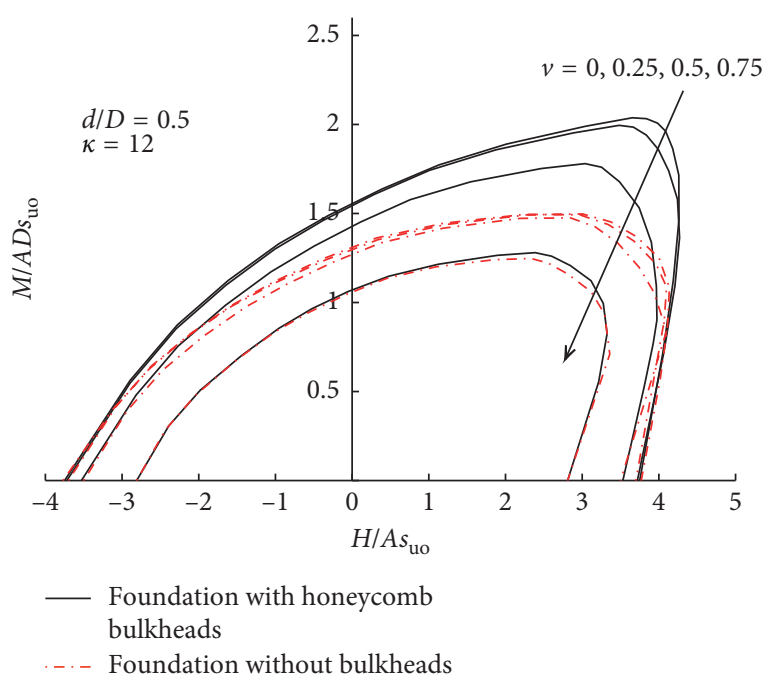

(b)

Figure 13: Comparison of failure envelopes under different vertical loads. (a) $d / D=0.1, \kappa=12$. (b) $d / D=0.5$, and $\kappa=12$.

foundations also decrease accordingly, indicating the weaken of the honeycomb bulkheads influence. In particular, when $d / D=0.5$ and $\nu=0.75$, the failure envelopes of the two types of foundations almost overlap, so the honeycomb bulkheads almost have no effects.

When $d / D=0.1$, the maximum moment bearing capacity of the bucket foundation with honeycomb bulkheads appears in the first quadrant of the HM load space. However, the maximum moment bearing capacity of the bucket foundation without bulkheads appears in the second quadrant (i.e., the $H$ and $M$ are in the reverse direction). As $H$ and $M$ always appear in the same direction in practice, i.e., the first quadrant of the HM load space, the honeycomb bulkheads have a positive effect on improving bearing capacities. When $d / D=0.5$, the shape difference between the failure envelopes of two foundations becomes very small, both inclines rightward, and the maximum moment bearing capacity of the two foundations appears in the first quadrant of the HM load space.

The above studies indicate that for nonhomogeneous clay, the smaller the vertical load $\nu$, the more obvious the influence of the honeycomb bulkheads. For a comparatively small embedment ratio $d / D$, the honeycomb bulkheads can change the shape of the failure envelopes, thus making the maximum moment capacity areas of the $H$ and $M$ appear in the same directions. Therefore, for a comparatively small vertical load $v$ or embedment ratio $d / D$, the honeycomb bulkheads can significantly improve the bearing capacity of the foundation; that is, the bucket foundation with honeycomb bulkheads is more stable and safer.

4.2. Approximating Expression. Figures 12 and 13 show that the failure envelopes in the HM load space are asymmetrical 
about the $H$ - and $M$-axes. The size and shape of the failure envelopes are dependent on the embedment ratio $d / D$, soil shear strength heterogeneity index $\kappa$, and vertical load $\nu$, and the conclusion is consistent with that of experimental studies $[39,40]$ and numerical simulations $[5,37,41]$.

The failure envelope of the bucket foundation with honeycomb bulkheads can be obtained by the following approximate expression:

$$
\left(\left|\frac{h}{h^{*}}\right|\right)^{\alpha}+\left(\frac{m}{m^{*}}\right)^{\alpha}+2 \beta \frac{h m}{h^{*} m^{*}}=1 .
$$

Equation (17) is a function of the $d / D$ ratio and $\kappa$. This expression is defined by an elliptical expression proposed by Gourvenec et al. [7] for skirted foundations. After that, Vulpe et al. $[4,5]$ used this expression to predict the failure envelope shape of a circular shallow foundation. In this study, the values of the fitting parameters were given based on the FE results of failure envelopes.

Here, $h=H / H_{\text {ult }}$ and $m=M / M_{\text {ult }}$, and $\alpha$ and $\beta$ are fitting parameters that rely on $d / D$ and $\kappa$, as presented in Table 4 . Fitting parameters $\alpha$ and $\beta$ can be interpolated for intermediate values of $d / D$ and $\kappa . h^{*}$ and $m^{*}$ are functions of $\nu=V / V_{\text {ult }}$, and the effect of vertical load on the failure envelopes can be considered.

Figure 14 shows the failure envelopes of bucket foundation with honeycomb bulkheads in normalized $v h$ and $v m$ load space for $0.1 \leq d / D \leq 0.5$, and $0 \leq \kappa \leq 30$. Each point in the figure represents a certain point of the failure envelope at $d / D$ and $k$. Although these points are somewhat discrete with the changes in $d / D$ and $\kappa$, they generally maintain a consistent trend. A power law expression defines a conservative curve fit to the lower ultimate of normalized $v h$ and $v m$ interaction, as shown in equations (18) and (19). The FE results for all $d / D$ ratios and $\kappa$, fall outside the fitted curve. $h^{*}$ and $m^{*}$ describe the interactions in the $\nu h$ and $\nu m$ load space, respectively, and the lowest horizontal or moment load in a known applied $v$ :

$$
\begin{aligned}
& h^{*}=1-v^{q}, \\
& m^{*}=1-v^{p},
\end{aligned}
$$

where $q=4.83$ and $p=3.25$.

Figure 15 compares the FE results with the approximating expression in normalized load space for $d / D=0.3$ and $\kappa=12$. Figure 15 (a) shows that the approximating expression result is most similar to the FE result when $\nu=0.75$, and the approximating expression becomes increasingly conservative for a low vertical load $\nu$ because the fitting parameters $\alpha$ and $\beta$ were solved by fitting them to the most conservative solution of the normalized $H M$ failure envelopes. However, the approximating expression can successfully capture changes in shape associated with $d / D$ and $\kappa$. Figure 15(b) shows that when setting the vertical load $v$ to a large value, the failure envelope gap between FE results and the approximating expression is comparatively small and slightly increases with the
TABLE 4: Fitting parameters $\alpha$ and $\beta$ for approximating expression.

\begin{tabular}{lcccccccccc}
\hline \multicolumn{1}{c}{$\alpha$} & \multicolumn{1}{c}{$d / D d / D$} \\
$\kappa$ & \multicolumn{1}{c}{$\alpha=0.1$} & & & & & \\
& 0.1 & 0.2 & 0.3 & 0.4 & 0.5 & 0.1 & 0.2 & 0.3 & 0.4 & 0.5 \\
\hline 0 & 1.92 & 2.25 & 2.36 & 2.32 & 2.54 & -0.20 & -0.40 & -0.51 & -0.63 & -0.75 \\
3 & 1.85 & 1.95 & 2.30 & 2.22 & 2.12 & -0.13 & -0.34 & -0.42 & -0.55 & -0.64 \\
6 & 1.81 & 2.06 & 2.16 & 2.12 & 2.23 & -0.03 & -0.25 & -0.38 & -0.52 & -0.61 \\
12 & 2.01 & 2.10 & 2.12 & 1.98 & 2.11 & 0.01 & -0.19 & -0.36 & -0.49 & -0.60 \\
30 & 2.21 & 2.15 & 2.10 & 2.05 & 2.08 & 0.02 & -0.15 & -0.30 & -0.45 & -0.58
\end{tabular}

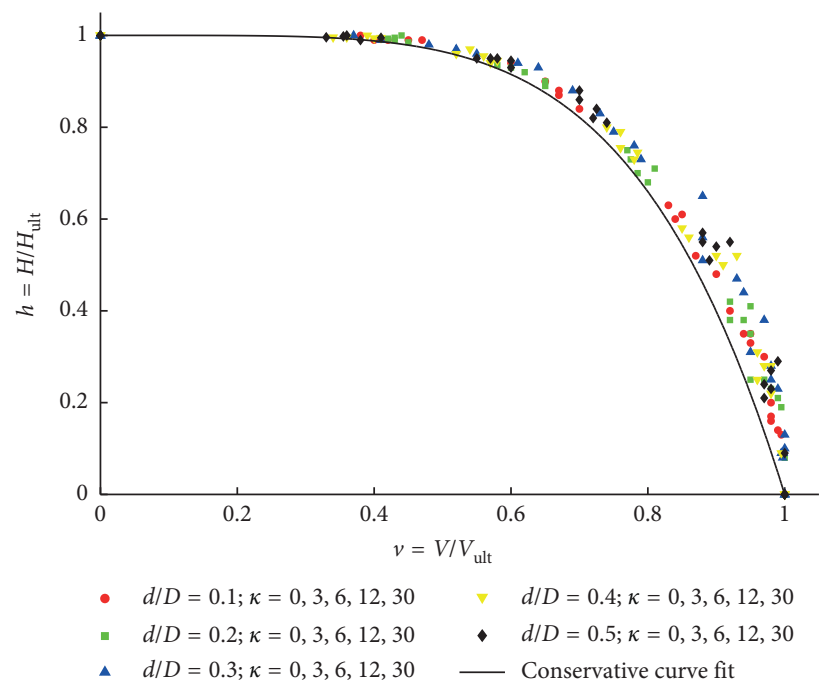

(a)

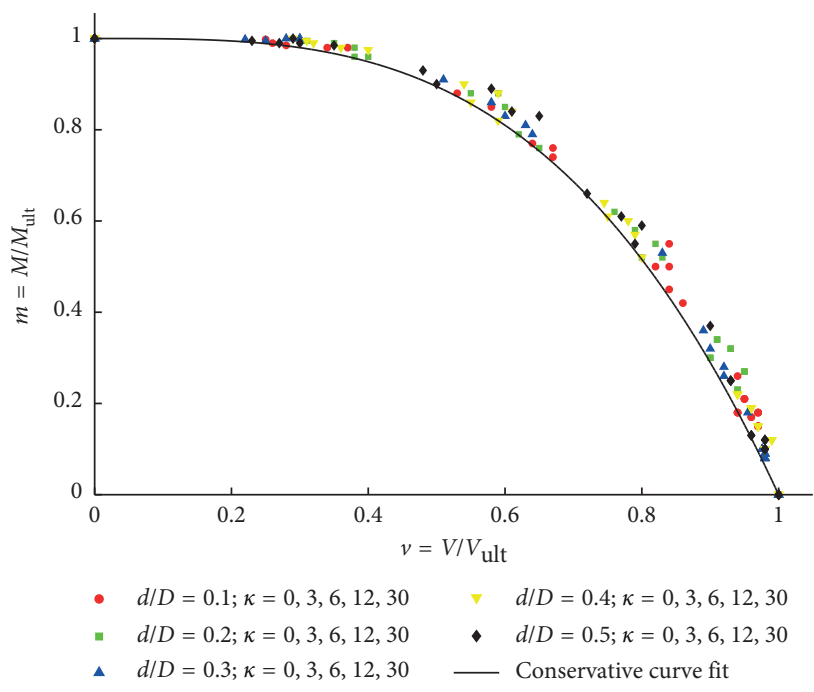

(b)

Figure 14: Definition of the lower limit to normalized $\nu h$ and $\nu m$ interactions. (a) $v h$ load space. (b) $v m$ load space.

decrease of $v$ in the $h m$ load space. Nonetheless, the predictions of ultimate states under combined VHM loading using equation (17) are considerably less conservative than the predictions resulting from the methods 


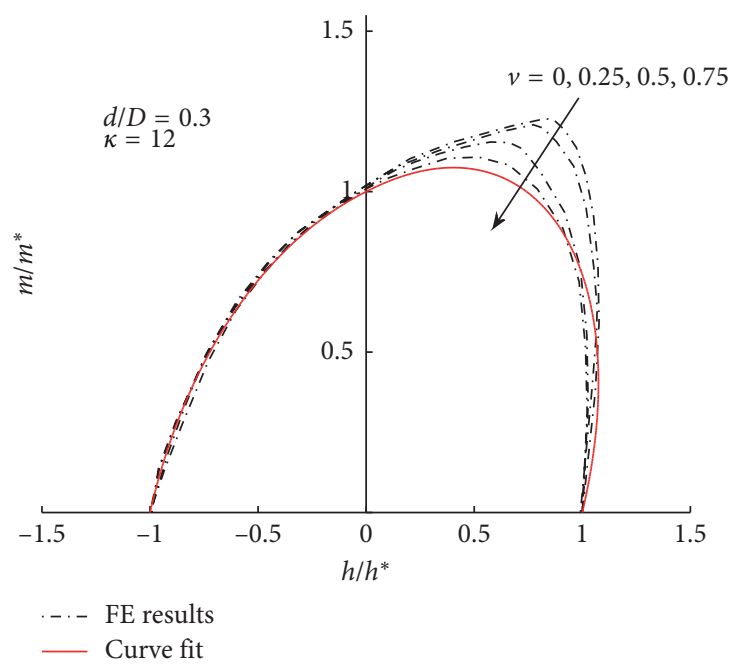

(a)

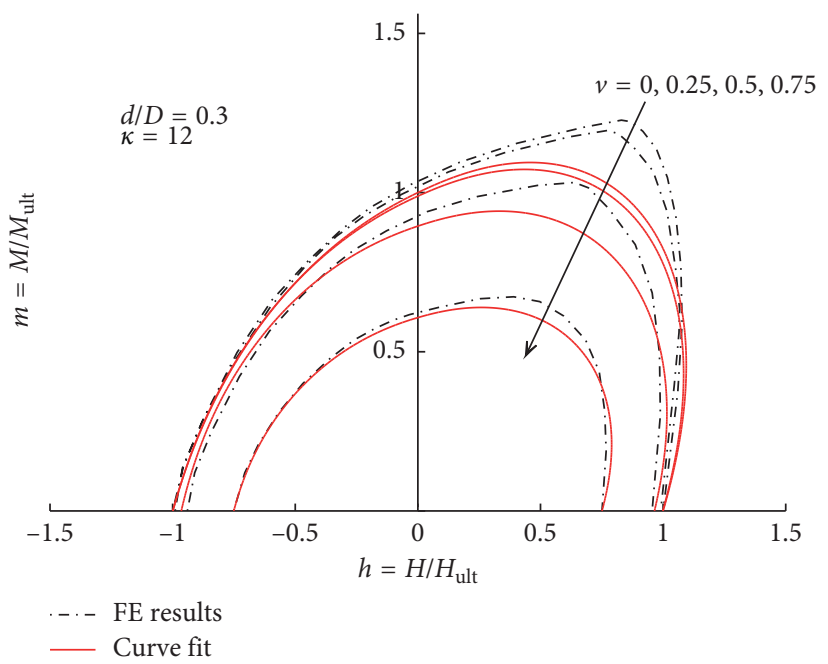

(b)

FiguRE 15: Comparison of failure envelopes between FE results and approximating expression. (a) $h / h^{*}-m / m^{*}$ load space. (b) $h m$ load space.

based on classical bearing capacity theory, which has been demonstrated explicitly $[5,7]$.

\section{Conclusions}

In this study, a series of 3D FE analyses were carried out to explicitly evaluate the undrained bearing capacities of the wide-shallow bucket foundations with and without honeycomb bulkheads under uniaxial and combined loadings, respectively. The effect of honeycomb bulkheads on the bearing capacities of the wide-shallow bucket foundation under different conditions was analysed as well. The main conclusions were drawn as follows:

(1) For homogeneous clay, the uniaxial vertical, horizontal, and moment bearing capacities of the wideshallow bucket foundation are basically unaffected by the honeycomb bulkheads. The honeycomb bulkheads also have almost no impact on the failure envelopes of the wide-shallow bucket foundation under combined VHM loading.

(2) For nonhomogeneous clay, the honeycomb bulkheads have little effect on improving the vertical or horizontal bearing capacity of the wide-shallow bucket foundation. However, the moment bearing capacity is considerably enhanced by the honeycomb bulkheads. The enhancement effects will increase with the increase in $\kappa$, and it reaches the maximum when $d / D=0.2$ or 0.3 for a certain $\kappa$.

(3) For nonhomogeneous clay, the honeycomb bulkheads can enhance the bearing capacities of the wideshallow bucket foundation under combined VHM loading. The enhancement effects will increase with the increase in $\kappa$, but decrease with the increase in $v$.

(4) For nonhomogeneous clay, the shape of the failure envelopes of the wide-shallow bucket foundation can be obviously changed due to the existence of the honeycomb bulkheads in a condition of comparatively small $d / D$.

(5) The simplified equations for the uniaxial bearing capacities of the wide-shallow bucket foundation with honeycomb bulkheads were proposed, thereby introducing the bearing capacity factors as the function of $d / D$ and $\kappa$.

(6) An elliptical approximating expression was used to predict the failure envelopes for the wide-shallow bucket foundation with honeycomb bulkheads under combined VHM loading. The fitting parameters in the expression were provided in a tabulated form.

\section{Data Availability}

The data used to support the findings of this study are available from the corresponding author upon request.

\section{Disclosure}

Dr. Yunfei Guan is treated as co-author.

\section{Conflicts of Interest}

The authors declare that there are no conflicts of interest.

\section{Acknowledgments}

The authors are grateful to the National Natural Science Foundation of China (Grant no. 51609147), Natural Science Foundation of Jiangsu Province (Grant no. BK20171129), and Fundamental Research Funds for the Central Research Institutes (Grant nos. Y317011 and Y319006). 


\section{References}

[1] X. Wang, X. Zeng, J. Li, X. Yang, and H. Wang, "A review on recent advancements of substructures for offshore wind turbines," Energy Conversion and Management, vol. 158, pp. 103-119, 2018.

[2] K.-Y. Oh, W. Nam, M. S. Ryu, J.-Y. Kim, and B. I. Epureanu, "A review of foundations of offshore wind energy convertors: current status and future perspectives," Renewable and Sustainable Energy Reviews, vol. 88, pp. 16-36, 2018.

[3] G. T. Houlsby and C. M. Martin, "Undrained bearing capacity factors for conical footings on clay," Géotechnique, vol. 53, no. 5, pp. 513-520, 2003.

[4] C. Vulpe, S. Gourvenec, and M. Power, "A generalised failure envelope for undrained capacity of circular shallow foundations under general loading," Géotechnique Letters, vol. 4, no. 3, pp. 187-196, 2014.

[5] C. Vulpe, "Design method for the undrained capacity of skirted circular foundations under combined loading: effect of deformable soil plug," Géotechnique, vol. 65 , no. 8 , pp. 669-683, 2015.

[6] L. C. Hung and S.-R. Kim, "Evaluation of undrained bearing capacities of bucket foundations under combined loads," Marine Georesources \& Geotechnology, vol. 32, no. 1, pp. 76-92, 2013.

[7] S. Gourvenec and S. Barnett, "Undrained failure envelope for skirted foundations under general loading," Géotechnique, vol. 61, no. 3, pp. 263-270, 2011.

[8] R. Liu, L. Wang, H. Y. Ding, J. J. Lian, and B. R. Li, "Failure envelopes of large-diameter shallow buried bucket foundation in undrained saturated soft clay under combined loading conditions," Chinese Journal of Geotechnical Engineering, vol. 36, no. 1, pp. 146-154, 2014.

[9] L. C. Hung and S. R. Kim, "Evaluation of vertical and horizontal bearing capacities of bucket foundations in clay," Ocean Engineering, vol. 52, pp. 75-82, 2012.

[10] A. Barari and L. B. Ibsen, "Undrained response of bucket foundations to moment loading," Applied Ocean Research, vol. 36, pp. 12-21, 2012.

[11] J.-S. Park and D. Park, "Vertical bearing capacity of bucket foundation in sand overlying clay," Ocean Engineering, vol. 134, pp. 62-76, 2017.

[12] T. Stergiou, D. Terzis, and K. Georgiadis, "Undrained bearing capacity of tripod skirted foundations under eccentric loading," Geotechnik, vol. 38, no. 1, pp. 17-27, 2015.

[13] D. S. K. Mana, S. Gourvenec, and C. M. Martin, "Critical skirt spacing for shallow foundations under general loading," Journal of Geotechnical and Geoenvironmental Engineering, vol. 139, no. 9, pp. 1554-1566, 2013.

[14] H. Ding, Y. Liu, P. Zhang, and C. Le, "Model tests on the bearing capacity of wide-shallow composite bucket foundations for offshore wind turbines in clay," Ocean Engineering, vol. 103, pp. 114-122, 2015.

[15] M. Liu, J. Lian, and M. Yang, "Experimental and numerical studies on lateral bearing capacity of bucket foundation in saturated sand," Ocean Engineering, vol. 144, pp. 14-20, 2017.

[16] X. Y. Wang, P. Y. Zhang, H. Y. Ding, and R. Liu, "Experimental study of the accumulative deformation effect on wide-shallow composite bucket foundation for offshore wind turbines," Journal of Renewable Sustainable Energy, vol. 9, no. 6, Article ID 063306, 2017.

[17] N. Jia, P. Zhang, Y. Liu, and H. Ding, "Bearing capacity of composite bucket foundations for offshore wind turbines in silty sand," Ocean Engineering, vol. 151, pp. 1-11, 2018.
[18] J. J. Lian, W. He, M. D. Wu, and H. J. Wang, "Experimental study of bearing characteristic of bucket foundation of offshore wind turbine with bulkheads," Rock and Soil Mechanics, vol. 37, no. 10, pp. 2746-2752, 2016.

[19] P. Ma, R. Liu, J. Lian, and B. Zhu, "An investigation into the lateral loading response of shallow bucket foundations for offshore wind turbines through centrifuge modeling in sand," Applied Ocean Research, vol. 87, pp. 192-203, 2019.

[20] X. Wang, X. Yang, and X. Zeng, "Centrifuge modeling of lateral bearing behavior of offshore wind turbine with suction bucket foundation in sand," Ocean Engineering, vol. 139, pp. 140-151, 2017.

[21] X. Wang, X. Yang, and X. Zeng, "Lateral response of improved suction bucket foundation for offshore wind turbine in centrifuge modelling," Ocean Engineering, vol. 141, pp. 295307, 2017.

[22] Y. G. Liu, P. Y. Zhang, H. Y. Ding, and Z. Zhang, "Load bearing characteristics of composite bucket foundation for offshore wind turbines," Journal of Marine Science Technology, vol. 24, no. 4, pp. 790-797, 2016.

[23] S. He, P. Zhang, and H. Ding, "Study on the bearing mode and force transfer path of composite bucket foundations," Energies, vol. 10, no. 7, p. 1041, 2017.

[24] P. Zhang, Y. Xu, C. Le, H. Ding, and Y. Guo, "Structural optimization method for the transition section in composite bucket foundations of offshore wind turbines," Energies, vol. 11, no. 11, p. 3230, 2018.

[25] C. H. Le, H. Y. Ding, and P. Y. Zhang, "Influences of bulkheads on the bearing mode of concrete bucket foundation for offshore wind turbine," Engineering Mechanics, vol. 30, no. 4, pp. 429-434, 2013.

[26] L. Sun, Z. Huo, and S. Yan, "Numerical studies on the working mechanism and bearing capacity of bucket foundations for offshore wind turbines," Journal of Coastal Research, vol. 73, pp. 478-482, 2015.

[27] Z. Xiao, B. R. Ge, Y. Z. Wang, and Y. Wang, "Influence of cruciform inner clapboards on uniaxial bearing capacity and failure mode of bucket foundation," Rock and Soil Mechanics, vol. 38, no. 11, pp. 3136-3144, 2017.

[28] W. X. Li, Horizontal bearing characteristics of composite bucket foundation for offshore wind turbine, Ph.D. Thesis, Nanjing Hydraulic Research Institute, Nanjing, China, 2018.

[29] Z. Xiao, B. Ge, and Y. Wang, "Capacities and failure modes of suction bucket foundation with internal bulkheads," Journal of Ocean University of China, vol. 16, no. 4, pp. 627-634, 2017.

[30] G. Yun and M. F. Bransby, "The undrained vertical bearing capacity of skirted foundations," Soils and Foundations, vol. 47, no. 3, pp. 493-505, 2007.

[31] G. Yun and M. F. Bransby, "The horizontal-moment capacity of embedded foundations in undrained soil," Canadian Geotechnical Journal, vol. 44, no. 4, pp. 409-424, 2007.

[32] R. Butterfield, G. T. Houlsby, and G. Gottardi, "Standardized sign conventions and notation for generally loaded foundations," Géotechnique, vol. 47, no. 5, pp. 1051-1054, 1997.

[33] M. Mosallanezhad, N. Hataf, and A. Ghahramani, "Experimental study of bearing capacity of granular soils, reinforced with innovative grid-anchor system," Geotechnical and Geological Engineering, vol. 26, no. 3, pp. 299-312, 2007.

[34] C. M. Martin, "New software for rigorous bearing capacity calculations," in Proceedings of the British Geotechnical Association International Conference on Foundations, Dundee, England, September 2003.

[35] R. A. Coffman, R. M. El-Sherbiny, A. F. Rauch, and R. E. Olson, "Measured horizontal capacity of suction 
Caissons," in Proceedings of the Offshore Technology Conference, Houston, Texas, USA, May 2004.

[36] Y. G. Liu, Bearing characteristics of composite bucket foundation for offshore wind turbine, Ph.D. Thesis, Tianjin University, Tianjin, China, 2014.

[37] S. Gourvenec and M. Randolph, "Effect of strength nonhomogeneity on the shape of failure envelopes for combined loading of strip and circular foundations on clay," Géotechnique, vol. 53, no. 6, pp. 575-586, 2003.

[38] M. F. Randolph and A. M. Puzrin, "Upper bound limit analysis of circular foundations on clay under general loading," Géotechnique, vol. 53, no. 9, pp. 785-796, 2003.

[39] C. M. Martin and G. T. Houlsby, "Combined loading of spudcan foundations on clay: laboratory tests," Géotechnique, vol. 50, no. 4, pp. 325-338, 2000.

[40] Y. Zhang, M. J. Cassidy, and B. Bienen, "A plasticity model for spudcan foundations in soft clay," Canadian Geotechnical Journal, vol. 51, no. 6, pp. 629-646, 2014.

[41] C. M. Martin and G. T. Houlsby, "Combined loading of spudcan foundations on clay: numerical modelling," Géotechnique, vol. 51, no. 8, pp. 687-699, 2001. 


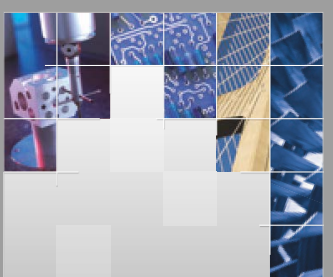

\section{Enfincering}
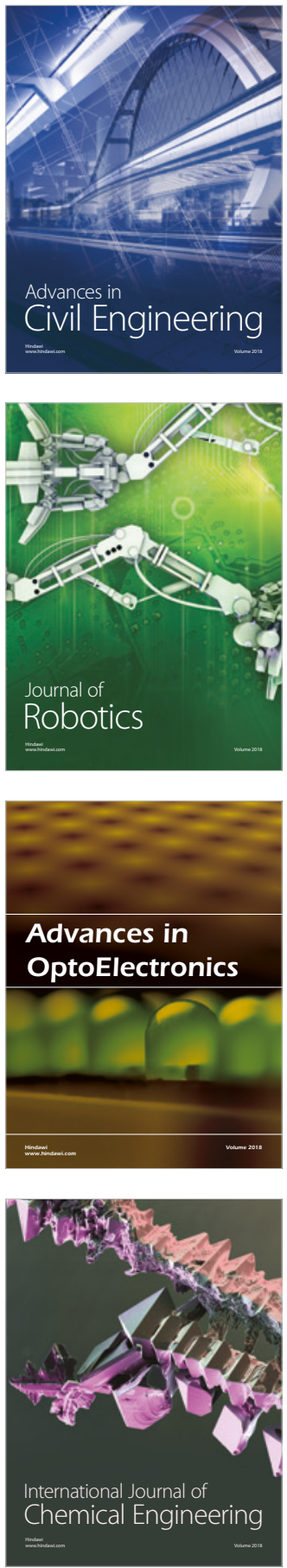

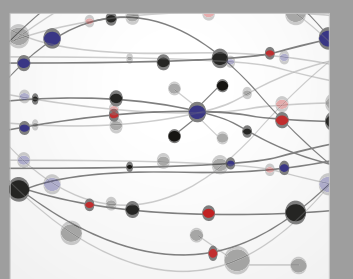

\section{Rotating \\ Machinery}

The Scientific World Journal

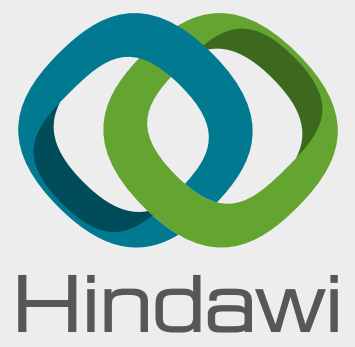

Submit your manuscripts at

www.hindawi.com
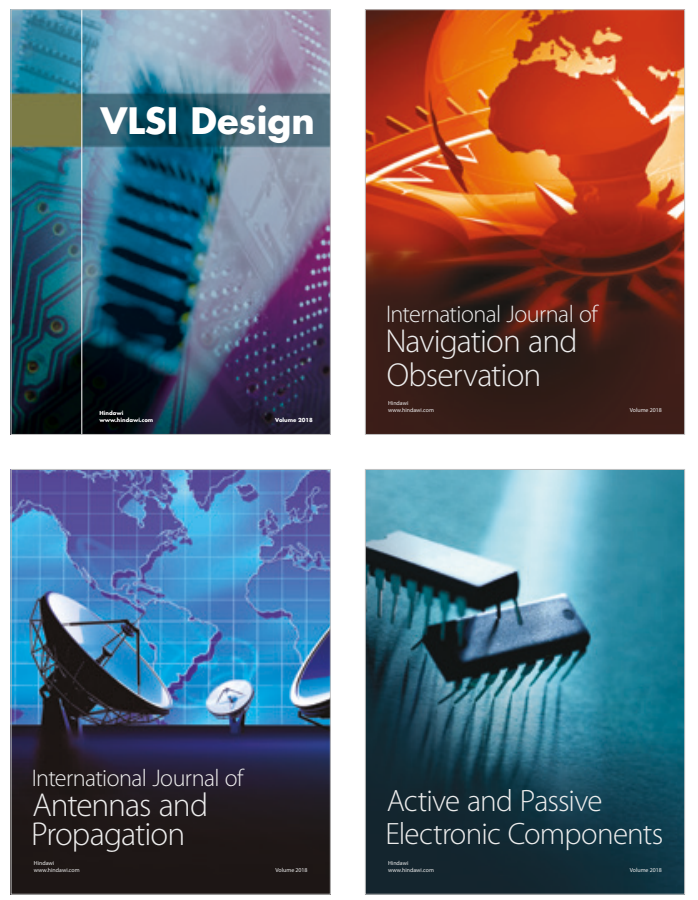
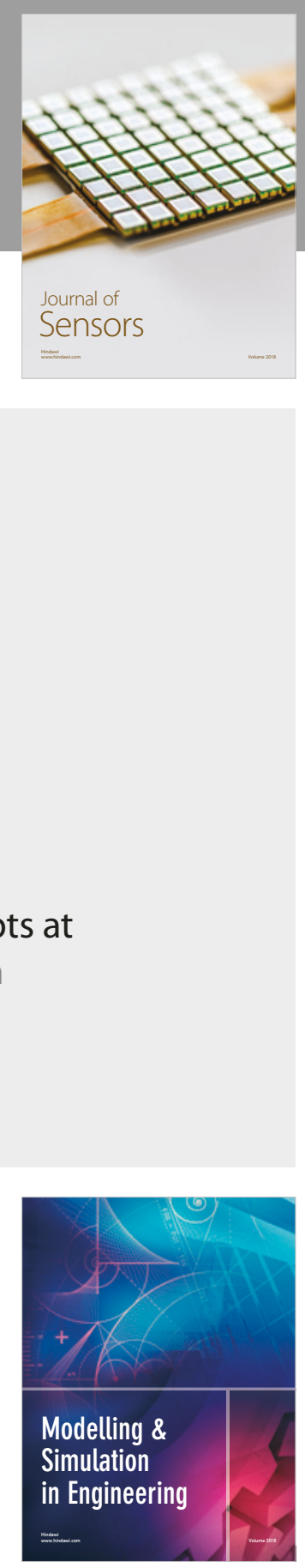

\section{Advances \\ Multimedia}
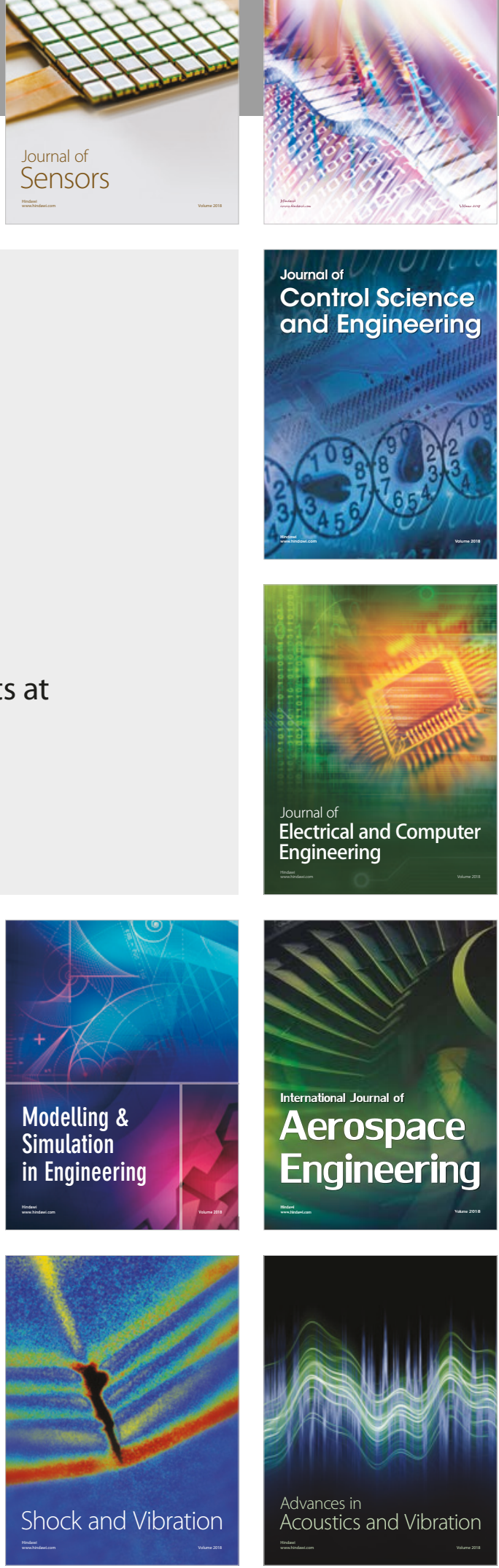